to calculate responses at Week 52 were included and grouped according to the CDAPSA categories reached at Week 52 (REM: $\leq 4$; LDA: $>4$ to $\leq 13$; moderate disease activity: $>13$ to $\leq 27$; high disease activity: $>27$ ). We then traced their mean cDAPSA trajectory from BL to Week 52. Mean disease activity in core PsA domains were reported longitudinally by cDAPSA category reached at Week 52 .

Results: A total of 375 APR subjects were included in the analyses. Achievement of REM or LDA by Week 52 was associated with lower mean CDAPSA at BL, and these subjects had continuous improvements in disease activity from BL to Week 52 (Figure). Among subjects who achieved REM or LDA by Week 52, most were classified as having LDA (mean cDAPSA: 8.5 ) or moderate disease activity (mean cDAPSA: 16.6), respectively, at Week 16. Furthermore, subjects who achieved REM or LDA by Week 52 showed early improvement, with no/mild articular and extra-articular disease activity by Week 52 with APR (Table).

Conclusion: In the subgroup of subjects who achieved cDAPSA REM or LDA, early improvement was seen in disease activity by Week 16 and sustained to Week 52 with continued treatment. Subjects achieving cDAPSA REM or LDA exhibited no or mild disease activity in enthesitis, dactylitis, function and skin psoriasis by Week 52 .

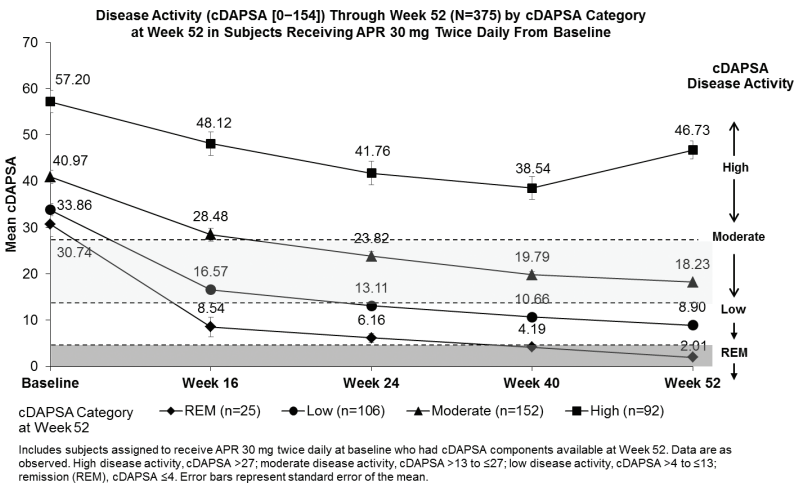

Articular and Extra-Articular Disease Activity in Subjects With REM or LDA at Week 52

\begin{tabular}{|c|c|c|c|c|c|c|c|c|}
\hline & \multicolumn{4}{|c|}{$\begin{array}{c}\text { Subjects With REM at Week } 52 \\
n=25\end{array}$} & \multicolumn{4}{|c|}{$\begin{array}{l}\begin{array}{l}\text { Subjects With LDA at Week } 52 \\
n=106\end{array} \\
\end{array}$} \\
\hline & & & & & & & & \\
\hline \multirow[b]{2}{*}{ Mean } & & Week & Week & Week & & Week & Week & Week \\
\hline & BL & 16 & 24 & 52 & $\mathrm{BL}$ & 16 & 24 & 52 \\
\hline SJC ( 0-66) & 9.1 & 2.2 & 1.2 & 0.1 & 8.8 & 3.5 & 2.0 & 1.1 \\
\hline TJC $(0-68)$ & 12.2 & 3.2 & 1.8 & 0.4 & 14.8 & 6.1 & 4.5 & 2.5 \\
\hline PAP (VAS 0-100 mm) & 50.6 & 14.4 & 13.1 & 7.2 & 51.2 & 32.5 & 32.5 & 25.1 \\
\hline PtGA (VAS $0-100 \mathrm{~mm})$ & 44.5 & 17.0 & 18.6 & 7.7 & 51.5 & 38.7 & 34.2 & 28.0 \\
\hline PhGA (VAS 0-100 mm) & 48.8 & 16.0 & 12.4 & 8.4 & 50.7 & 24.0 & 18.9 & 13.7 \\
\hline PASI $^{*}(0-72)$ & 9.5 & 4.2 & 3.5 & 2.7 & 8.2 & 3.7 & 3.4 & 4.0 \\
\hline MASES§ $(0-13)$ & 1.9 & 0.4 & 0.1 & 0.4 & 3.3 & 1.7 & 1.2 & 1.2 \\
\hline Dactylitis count ${ }^{\ddagger}$ & 2.3 & 0.7 & 0.2 & 0.0 & 2.8 & 1.0 & 0.6 & 0.5 \\
\hline HAQ-DI $(0-3)$ & 0.9 & 0.3 & 0.2 & 0.1 & 1.0 & 0.7 & 0.7 & 0.6 \\
\hline
\end{tabular}

Disclosure of Interests: Laura C Coates Grant/research support from: AbbVie, Celgene, Lilly, Novartis and Pfizer, Consultant for: AbbVie, Amgen, BMS, Celgene, Galapagos, Gilead Sciences Inc., Janssen, Lilly, Novartis, Pfizer, Prothena Corp and UCB, Philip J Mease Grant/research support from: AbbVie, Amgen, BMS, Celgene, Janssen, Lilly, Novartis, Pfizer, SUN and UCB, Consultant for: AbbVie, Amgen, BMS, Galapagos, Gilead Sciences, Inc., Janssen, Lilly, Novartis, Pfizer, SUN and UCB, Speakers bureau: AbbVie, Amgen, BMS, Celgene, Genentech, Janssen, Lilly, Novartis, Pfizer and UCB, Frank Behrens Grant/research support from: AbbVie, Pfizer, Roche, Chugai, Prophylix, Bioline, Novartis, Consultant for: AbbVie, Pfizer, Roche, Chugai, UCB, Bristol-Myers Squibb, Celgene, MSD, Novartis, Biotest, Janssen, Genzyme, Eli Lilly, Speakers bureau: Ad board: AbbVie, Pfizer, Roche, Chugai, UCB, Bristol-Myers Squibb, Celgene, Novartis, Biotest, Janssen, Genzyme, Eli Lilly, Ana-Maria Orbai Grant/research support from: AbbVie, Celgene, Horizon Pharma, Janssen, Lilly, and Novartis, Consultant for: Lilly, Janssen, Novartis, Pfizer, and UCB, Alexis Ogdie Grant/research support from: (To my university) Novartis, Pfizer, Grant/research support from: Novartis, Pfizer, Grant/research support from: Novartis, Pfizer, Grant/research support from: Novartis, Pfizer, Consultant for: AbbVie, Bristol-Myers Squibb, Celgene, Corrona, Eli Lilly and Company, Novartis, Pfizer, and Takeda, Consultant for: AbbVie, Amgen, Bristol-Myers Squibb, Celgene, Corrona, Eli Lilly, Novartis, Pfizer Inc, Takeda, Consultant for: Abbvie, Amgen, BMS, Celgene, Corrona, Lilly, Novartis, Pfizer, Takeda, Consultant for: Abbvie Amgen, BMS, Celgene, Corrona, Lilly, Novartis, Pfizer, Takeda, Michele Brunori Employee of: Celgene Corporation, Lichen Teng Employee of Celgene Corporation, Benoit Guerette Employee of: Celgene Corporation, Josef S. Smolen Grant/research support from: AbbVie, Eli Lilly, Janssen, MSD, Pfizer, Roche, Consultant for: AbbVie, Amgen, Astra-Zeneca, Astro, Celgene Corporation, Celtrion, Eli Lilly, Glaxo, ILTOO, Janssen, Medlmmune, MSD, Novartis, Pfizer, Roche, Samsun, Sanofi, UDB, Speakers bureau: AbbVie, Amgen, Astra-Zeneca, Astro, Celgene Corporation, Celtrion, Eli Lilly, Glaxo, ILTOO, Janssen, Medlmmune, MSD, Novartis, Pfizer Roche, Samsun, Sanofi, UDB DOI: 10.1136/annrheumdis-2019-eular.1645

\section{AB0742 ACHIEVEMENT OF PASDAS LOW DISEASE ACTIVITY AND VERY LOW DISEASE ACTIVITY IN PATIENTS WITH PSORIATIC ARTHRITIS TREATED WITH CERTOLIZUMAB PEGOL OVER 4 YEARS AND THE OVERLAP WITH DAPSA AND MDA DISEASE ACTIVITY TARGETS}

Laura C. Coates ${ }^{1}$, Joseph F. Merola ${ }^{2}$, Oliver Fitzgerald ${ }^{3}$, Arthur Kavanaugh ${ }^{4}$, Alice B. Gottlieb ${ }^{5}$, William Tillett ${ }^{6}$, Lars Bauer ${ }^{7}$, Bengt Hoepken ${ }^{7}$, Tommi Nurminen ${ }^{7}$, Philip J. Mease ${ }^{8}$, Philip Helliwell ${ }^{9}$, Désirée van der Heijde ${ }^{10} .{ }^{1}$ Nuffield Orthopaedic Centre, Oxford, United Kingdom, ${ }^{2}$ Brigham and Women's Hospital, Harvard Medical School, Boston, MA, United States of America; ${ }^{3}$ St Vincent's University Hospital and Conway Institute for Biomolecular Research, University College Dublin, Dublin, Ireland; ${ }^{4}$ Division of Rheumatology Allergy and Immunology, UC San Diego School of Medicine, La Jolla, CA, United States of America;

${ }^{5}$ Department of Dermatology, ICahn School of Medicine at Mt Sinai, New York, NY, United States of America; ${ }^{6}$ Royal National Hospital for Rheumatic Diseases, Bath, United Kingdom; ${ }^{7}$ UCB Pharma, Monheim, Germany; ${ }^{8}$ Swedish Medical Center and University of Washington, Seattle, WA, United States of America; ${ }^{9}$ Leeds Institute of Rheumatic and Musculoskeletal Medicine, University of Leeds, Leeds, United Kingdom; ${ }^{10}$ Leiden University Medical Centre, Leiden, Netherlands

Background: Psoriatic Arthritis Disease Activity Score (PASDAS), ${ }^{1}$ Disease Activity Index for Psoriatic Arthritis (DAPSA), ${ }^{2}$ and the minimal disease activity (MDA) criteria ${ }^{3}$ are instruments recommended for evaluating disease activity (DA) in psoriatic arthritis (PsA). RAPID-PsA demonstrated the sustained efficacy of certolizumab pegol (CZP) across the spectrum of PsA symptoms. ${ }^{4}$ A substantial proportion of patients (pts) completing 4 years' treatment achieved DA targets; 75\% reached DAPSA low DA (LDA) or remission (REM), and almost $60 \%$ had MDA ( $\geq 5 / 7$ MDA criteria), half of whom also achieved very low DA (VLDA) (7/7 MDA criteria). ${ }^{5}$

Objectives: To report the proportion of pts who achieved PASDAS VLDA and LDA over 216 weeks' (wks') CZP treatment, and the overlap in pts achieving PASDAS, DAPSA and MDA

Methods: RAPID-PSA (NCT01087788) was double-blind and placebo-controlled to Wk24, dose-blind to Wk48, and open-label (OL) to Wk216. ${ }^{5}$ Outcomes reported for pts randomised to CZP at WkO (200 mg every 2 wks or $400 \mathrm{mg}$ every 4 wks, following a $400 \mathrm{mg}$ loading dose at Wks0/ $2 / 4)$ are PASDAS change from baseline (CFB); pts achieving PASDAS LDA $(>1.9-<3.2)$, PASDAS VLDA $(\leq 1.9)$, DAPSA LDA $(>4-\leq 14)$, DAPSA REM ( $\leq 4), M D A$ and VLDA to Wk216; and the overlap in pts achieving PASDAS VLDA, DAPSA REM, and VLDA, at Wk216. Data are summarized for observed cases per visit. Pts withdrawing between scheduled visits had their final assessment values assigned to the next scheduled visit timepoint

Results: Of 409 pts randomised, 273 received CZP from WkO, of whom $248(90.8 \%)$ completed Wk24 and $183(67.0 \%)$ completed Wk216. The mean (SD) baseline PASDAS was 6.0 (1.0): in the high DA range, CFB at Wk216 was -3.4 (1.5). Of pts completing Wk216, 66.3\% (118/178) were in PASDAS LDA or VLDA (PASDAS VLDA: $36.5 \%$ [n=65]): less than the proportion reaching DAPSA LDA or REM $(76.2 \%)$, but more than those achieving MDA or VLDA (57.8\%) (Figure A).

At Wk216, of pts achieving PASDAS VLDA, a large proportion (71\% [46/ 65]) had VLDA based on MDA criteria (Figure B1) and most (94\% [61/ 65]) achieved DAPSA REM (Figure B2). Almost all pts achieving VLDA $(96.1 \%$ [50/52]) were also in DAPSA REM (Figure B3). After 4 years' CZP treatment, $25.8 \%(46 / 178)$ pts achieved the PASDAS VLDA, DAPSA REM and VLDA. 
Figure: A) Patients with PsA achieving PASDAS, DAPSA and MDA disease activity targets over 4 years' CZP treatment $(O C)$

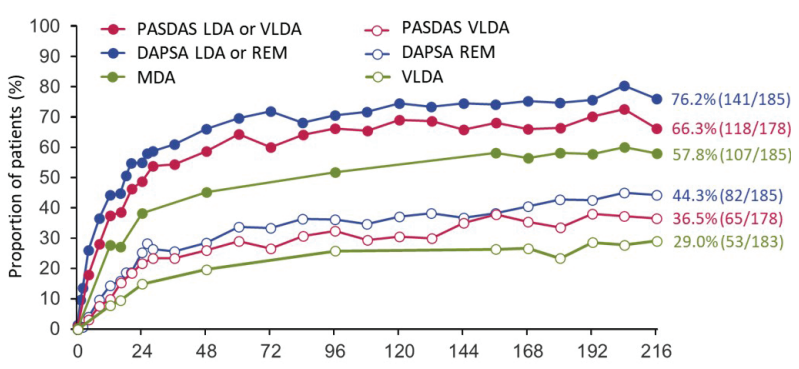

B) Overlap in patients with PSA achieving PASDAS VLDA, DAPSA REM and VLDA upon completing 216 weeks' CZP treatment $(O C)$

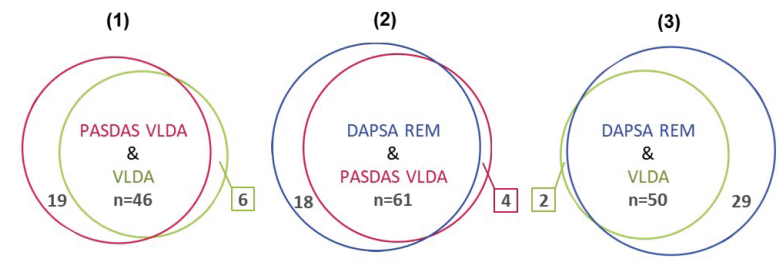

Data are for $\mathrm{OC}$ per visit. Patients withdrawing between scheduled visits had their final assessment values assigned to the next scheduled visit timepoint. CZP: certolizumab pegol; DAPSA: Disease Activityindex for PSoriatic Arthritis; ; DA: Iow diseaseactivity remission; VLDA: very low disease activity.

Conclusion: A substantial proportion of pts completing 4 years' CZP treatment achieved PASDAS LDA or VLDA, and the vast majority who achieved PASDAS VLDA at Wk216 also reached DAPSA REM and/or VLDA. 1 in 4 pts achieved the most stringent DA target with all 3 instruments.

\section{REFERENCES}

[1] Helliwell P. Ann Rheum Dis 2013;72:986-91; 2. Schoels M. Ann Rheum Dis 2016;75:811-18; 3. Coates L. Ann Rheum Dis 2010;69:48-53; 4. van der Heijde D. RMD Open 2018;4:e000582.

Acknowledgement: We thank the patients who participated. This study was funded by UCB Pharma, medical writing by Hinal Tanna, Costello Medical, UK

Disclosure of Interests: Laura C Coates Grant/research support from: AbbVie, Celgene, Lilly, Novartis and Pfizer, Consultant for: AbbVie, Amgen, BMS, Celgene, Galapagos, Gilead Sciences Inc., Janssen, Lilly, Novartis, Pfizer, Prothena Corp and UCB, Joseph F. Merola Consultant for: Biogen IDEC, Abbvie, Amgen, Eli Lilly and Company, Novartis, Pfizer, Janssen, UCB, Samumed, Celgene, Sanofi Regeneron, Merck, and GSK, Oliver FitzGerald: None declared, Arthur Kavanaugh Grant/research support from: UCB Pharma, Alice B Gottlieb Grant/research support from: PI: Incyte Corporation, Janssen-Ortho Inc., Lilly ICOS LLC, Novartis, UCB, XBiotech, Consultant for: AbbVie, Dermira, Incyte Corporation, Lilly ICOS LLC, Novartis, Sun Pharmaceutical Industries Ltd., Avotres (unpaid), XBiotech (unpaid), Speakers bureau: AbbVie, Eli Lilly and Company, Janssen Biotech; advisory board: Bristol-Myers Squibb, Celgene Corporation, Janssen Biotech, Janssen-Ortho Inc., LEO Pharma, Novartis, UCB, William Tillett Grant/research support from: AbbVie, Celgene, and Lilly, Consultant for: AbbVie, Celgene, Lilly, Novartis, and Pfizer, Speakers bureau: Abbvie, Celgene, Lilly, Janssen, Novartis, UCB, and Pfizer, Lars Bauer Employee of: Employee of UCB Pharma, Bengt Hoepken Employee of: Employee of UCB Pharma, Tommi Nurminen Employee of: Employee of UCB Pharma, Philip J Mease Grant/research support from: AbbVie, Amgen, BMS, Celgene, Janssen, Lilly, Novartis, Pfizer, SUN and UCB, Consultant for: AbbVie, Amgen, BMS, Galapagos, Gilead Sciences, Inc., Janssen, Lilly, Novartis, Pfizer, SUN and UCB, Speakers bureau: AbbVie, Amgen, BMS, Celgene, Genentech, Janssen, Lilly, Novartis, Pfizer and UCB, Philip Helliwell Grant/research support from: Paid to charity: from AbbVie, Janssen and Novartis, Consultant for: Paid to charity: from AbbVie, Amgen, Pfizer, and UCB and Celgene. Paid to self: from Celgene and Galapagos, Désirée van der Heijde Consultant for: AbbVie, Amgen, Astellas, AstraZeneca, Bristol-Myers Squibb, Boehringer Ingelheim, Celgene, Daiichi, EliLilly, Galapagos, Gilead, GlaxoSmithKline, Janssen, Merck, Novartis, Pfizer, Regeneron, Roche, Sanofi, Takeda, Union Chimique Belge DOI: 10.1136/annrheumdis-2019-eular.765

\section{AB0743 REAL-WORLD EFFECTIVENESS AND SAFETY OF APREMILAST IN BELGIAN PATIENTS WITH PSORIATIC ARTHRITIS: ANALYSIS FROM THE MULTICENTRE,} PROSPECTIVE, NON-INTERVENTIONAL APOLO STUDY

Kurt de Vlam ${ }^{1}$, Adrien Nzeusseu ${ }^{2}$, Marie-Joëlle Kaiser ${ }^{3}$, Johan Vanhoof ${ }^{4}$ Philip Remans ${ }^{4}$, Marthe Van den Berghe ${ }^{5}$, Silvana DI Romana ${ }^{6}$, Filip van den Bosch ${ }^{7}$, Sofie Leroux ${ }^{8}$, Virginie Vanhooff ${ }^{8}$, Rik Lories ${ }^{1} .{ }^{1}$ Skeletal Biology and Engineering Research Center, University Hospital Leuven, Leuven, Belgium; ${ }^{2}$ University Hospitals Saint-Luc, Brussels, Belgium; ${ }^{3}$ Department of Rheumatology, C.H.U. Sart Tilman, Liège, Belgium; ${ }^{4}$ Department of Rheumatology, ReumaClinic Genk, Genk, Belgium; ${ }^{5}$ Department of Rheumatology, ASZ Aalst, Aalst, Belgium; ${ }^{6}$ Department of Rheumatology, University Hospital Saint-Pierre, Brussels, Belgium; ${ }^{7}$ Department of Rheumatology, Ghent University Hospital, Gent, Belgium; ${ }^{8}$ Celgene BeLux, Braine-l'Alleud, Belgium

Background: Real-world evidence on effectiveness and safety data for patients (pts) with psoriatic arthritis (PsA) in the Belgium clinical practice setting is lacking.

Objectives: To assess the effectiveness and safety of apremilast (APR) in pts with active PsA from routine clinical practice in Belgium.

Methods: In this multicentre, prospective, non-interventional study (APOLO), the PsA Response Criteria (PsARC) response 6 months after APR initiation was the primary endpoint. PsARC response was defined as improvement in $\geq 2$ and no worsening of any of the following 4 meas ures: tender joint count (TJC; 0-68), swollen joint count (SJC; 0-66), Physician's Global Assessment of Disease Activity (PhGA) and Patient's Global Assessment of Disease Activity (PtGA). Other endpoints included PsAID12, HAQ-DI, Physician's and Patient's Numerical Rating Scale (NRS) assessing disease activity for the most affected joint, psoriasisaffected body surface area (BSA), enthesitis, dactylitis, pain and pruritus. The current analysis is based on observed data.

Results: The first 55 of a planned 150 Belgian pts receiving APR for up to 6 months were evaluated. Mean age was $52.5 \mathrm{yrs}$, mean BMI was $27.1 \mathrm{~kg} / \mathrm{m}^{2}$ and $47.3 \%$ were female. Mean durations of psoriasis and PsA were $15.8 \mathrm{yrs}$ and $8.1 \mathrm{yrs}$, respectively; $\approx 80 \%$ of pts were biologicnaive. At baseline (BL), mean (SD) SJC was 8.0 (5.4), mean (SD) TJC was 12.7 (9.5) and mean (SD) body surface affected was $12.3 \%$ (20.8\%); $31.0 \%$ of pts had dactylitis and $47.8 \%$ had enthesitis. In total, 35 pts $(63.6 \%)$ continued APR treatment for 6 months; 20 (36.4\%) had discontinued APR (insufficient effectiveness: 21.8\%; adverse events: $10.9 \%$, intolerance: $3.6 \%$ ). After 6 months of APR initiation, $69.6 \%$ of pts had a PsARC response. Mean changes from BL in SJC were -4.4 (Month 3) and -5.7 (Month 6), with improvements in SJC (defined as $\geq 30 \%$ decrease per PsARC) observed in most pts (Month 3: $78.3 \%$; Month 6: 83.3\%). Comparable results were seen for TJC: Mean changes from BL were -7.2 (Month 3) and -6.7 (Month 6), with improvements observed in most pts (Month 3: 78.3\%; Month 6: $80 \%$ ). Decreases in PhGA score of $>1$ from BL were observed in most pts at Months 3 $(73.7 \%)$ and $6(66.7 \%)$. Mean (SD) Physician's NRS scores decreased from 5.6 (2.6) at BL to 2.5 (2.0) at Month 6. Among pts with enthesitis at BL who had data available at Month $6,54.5 \%$ achieved a score of 0 Among pts with dactylitis at BL who had data available at Month 6 , $44.4 \%$ achieved a score of 0 . BL mean (SD) PsAID12 score of 5.9 (1.6) decreased to 3.7 (1.8) at Month 6. Mean (SD) BSA improved from $12.3 \%(20.8 \%)$ at $\mathrm{BL}$ to $7.5 \%(14.7 \%)$ at Month 6 . An improvement of $\geq 20 \%$ in HAQ-DI at Month 6 was achieved by $73.1 \%$ of pts. Improvements were also seen in PtGA score, overall pain and pruritus. No new safety and tolerability concerns from known overall safety profile of APR. Conclusion: Results from this real-world PsA study confirmed an improvement in disease activity with APR in both physician-assessed and ptreported outcomes for most pts. Overall, improvements were observed after 3 months of APR treatment and were maintained up to the 6-month observation period. Safety and tolerability were similar to the known profile of APR.

Disclosure of Interests: Kurt de Vlam Consultant for: Pfizer Inc, Consultant for: Johnson \& Johnson, Adrien Nzeusseu: None declared, MarieJoëlle Kaiser Consultant for: Celgene Corporation, Johan Vanhoof: None declared, Philip Remans: None declared, Marthe Van den Berghe: None declared, Silvana Di Romana: None declared, Filip van den Bosch Consultant for: AbbVie, BMS, Galapagos, Janssen, Lilly, Merck, Novartis, Pfizer and UCB, Speakers bureau: AbbVie, BMS, Janssen, Lilly, Merck, Novartis, Pfizer and UCB., Sofie Leroux Employee of: Celgene Corporation, Virginie Vanhooff Employee of: Celgene Corporation, Rik Lories Consultant for: Abbvie, Celgene, Eli-Lilly, Janssen, Merck, Novartis, Pfizer, UCB

DOI: 10.1136/annrheumdis-2019-eular.1862 